\title{
A Discussion on the Continuity of Higher Education and Physical Education's Relative Development
}

\author{
Renjie Song \\ Zhengzhou University of Industry Technology , Zhengzhou, Henan Province. 451150.
}

Keywords: Personnel talents; Physical education; Key point; Discussion

\begin{abstract}
. 30 years have passed since the opening up and reformation, during which we have reached a series of achievements in various fields. With the deepening development, the need of a large quantity of personnel talents is urgent. P.E., as a signal to judge if a country is developed, highlights the continuity of higher education and physical education's development. This essay tries to discuss the continuity of higher education and physical education's development.
\end{abstract}

\section{Introduction}

Building sports power is our national sports' focus. To establish a strong nation of sports, we must start from colleges and universities. Accompanied by China's emphasis on college physical education, and one after another enactment and implementation of relevant laws, such as "Sports Regulations", "National College Physical Education Teaching Guidance Outline" and "Students Physical Health Labeling". These regulations enable us to find out the adaptable methods for the personnel training and physical education in our country by referring to the western sports culture and adapting to the national conditions of our country. In this part, we can say that we have achieved some results, accumulated some experience, and some problems have also emerged.

\section{Problems Existing in the Continuity of Higher Education and Physical Education's Relative Development}

The fundamental task of colleges and universities is to train qualified personnel. The quality of personnel trained at school is the most important standard to measure the educational level of colleges and universities. In order to implement the new requirements put forward by the 18th National Congress of the Communist Party of China on education and the spirit of "Several Opinions of the Ministry of Education on Improving the Quality of Higher Education in an All-round Way", and further promote the reform and construction of physical education and comprehensively improve the quality of personnel training, we must attach importance to the talents training and physical education problems. Some problems in the cultivation of college sports talents in our country are listed below.

The Break of Higher Education and Physical Education's Development in the Level of Thoughts. In the traditional teaching, colleges and universities, as the foundations for cultivating and outputting talents, have always instilled such an idea that cultural studies are the focus of all teaching. In many universities there is not even a physical education lesson or a physical education lesson exists in name only. So that the higher education and physical education's development fail to be linked. This situation is particularly prominent in remote areas in the west. Coupled with the current education system, emphasizing on the rate of enrollment, and the achievement of the cultural class is the most important measure of a good school indicators, resulting in schools, students, parents ignore the physical education. These two aspects have caused the personnel training in colleges and universities and the development of physical education being congenitally deficient.

Problems in the Continuity of Higher Education and Physical Education's Development in the Level of Teachers. As a big country in population, and in education as well, the insufficient of long- 
term teachers, shortages of teachers and poor quality of teachers, have always been major issues that plague China's education. In the process of shortage of teachers, especially in colleges and universities which have set P.E., music, art, there is even worse shortage of teachers. Specialized teachers are in short. Most physical education teachers do not pay enough attention to teaching, they think that the focus of personnel training should be specialized courses in culture. There is no comprehensive understanding of physical education, and some think physical education is done doing exercises, running jogging and so on. They despise the teaching of student physical theory. Schools also lack the capacity to accommodate individual teachers, teachers are afraid to boldly appointed new ideas, resulting in few physical teachers in school. Another reason why the shortage of professional P.E. teachers leading to such a miserable situation is that most P.E. majors are switched. Schools do not attach importance to sports, and the treatment of sports teachers can be imagined. Sports teachers have no way out, so, they have to switch jobs, and engage in other aspects of teaching or another livelihood.

Problems of Teaching Material System in the Continuity of Higher Education and Physical Education's Development. Due to the lack of enough emphasis on physical education in colleges and universities, the construction of curriculum materials system with rich content, diverse forms and open sharing is greatly reduced around the needs of diversified talents training in colleges and universities. Shortage of educational funds make there being more issues on the development of curriculum resources, colleges and universities further promoting the development of curriculum, teaching materials, strengthening the project curriculum, teaching materials. It cannot provide students with rich sports library, case base, and fails to maximize the students' course requirements. In many schools, the number of newly-started courses is less than $3 \%$ of the total number of new courses in a few years. Innovative course organization, management mode and resource allocation methods and structurally optimized course teaching teams cannot be established. Teaching content is unable to establish a new mechanism, and cannot promptly introduce the latest achievements in various fields of domestic teaching. The fallback of teaching material system, makes us cannot match the developed countries sports development.

Problems of Teaching Practice in the Continuity of Higher Education and Physical Education's Development. Learning to use is everyone's pursuit of academic goals. To learn to use, for a teacher is puts practical teaching and theoretical teaching in an equally important position, and fully implements the basic requirements of practical teaching. According to the professional requirements of sports and personnel training requirements, they should establish the construction of practical teaching system scientifically, formulate practical teaching plan, practice teaching standard and practice achievement assessment method, rationally increase the proportion of practical teaching, reasonably achieve practical teaching time being no less than $50 \%$ of the total academic hours. However, in the past, the survey on physical education curriculum in colleges and universities shows that there is a serious mismatch between theoretical and practical teaching of college physical education. They either highlight theoretical teaching and ignore practical teaching, or highlight practical teaching and ignore theoretical teaching. The worst condition is that they ignore both practical teaching and theoretical teaching, and physical education is to play. When they highlight theoretical teaching and ignore practical teaching, the primary problems are those colleges and universities lacking of the funds to buy the equipment they need in their physical activity or they cannot build physical education. Taking swimming as an example, there are learning and practice about swimming chapters in physical education textbooks, but in practice, most schools cannot build swimming pools due to the large amount of costs. As a result, many studies in swimming teaching remain in the theory. When they highlight practical teaching and ignore theoretical teaching, there is a lack of teacher training in sports theory. It is quite normal as a matter of fact that most students think practice lighter than theory. As teachers, if they highlight theoretical teaching and ignore practical teaching, so long stay in the existing concept, the theory cannot be innovative, of course, in practice nothing can be innovative, too, which makes PE teaching personnel training and sports development stagnant. 
Problems of Selecting Personnel Talents in the Continuity of Higher Education and Physical Education's Development. Physical education is not without purpose. Universities can be said to be the national sports supernumerary found and training front. To cultivate sports talents to develop sports power, we must cultivate outstanding reserve talents for sports. All this must be started with young children and found out as soon as possible from an early age, laying a solid foundation as early as possible, making him/her to their full potential. As a country with large population, there are a large number of sporting stars hidden in the vast numbers of young children with sports potential. It is an important move to discover, select and train the sports reserve talents from the all-round development of the after-class sports training in colleges and universities. Colleges and universities should also correctly handle the popularization and improvement of teaching related issues, to ensure the teaching of physical education and extracurricular activities to be carried out and ensure that various forms of after-class sports training to be carried out. Timely detecting and focusing on training athletes, improving their skills level of exercise. However, among these things, nearly nothing has been done by most colleges and universities. The training of extracurricular sports training in schools has no emphasis. Some projects such as track and field, swimming, gymnastics, table tennis, badminton, basketball, volleyball and soccer cannot be targeted at students. So that students cannot play their due potential.

Problems of Sharing Good Teaching Resources in the Continuity of Higher Education and Physical Education's Development. The easiest way to share college teaching resources is to speed up the integration of P.E. information technology and teaching in colleges and universities. Promoting the construction of digital campus in colleges and universities and fully achieve diversification of physical education, practice and management in colleges and universities. Making full use of information technology to accelerate the integration of various high quality educational resources. Realizing all-round cooperation in sports among underdeveloped areas and developed areas and the integration of online teaching platform and teaching resource library, perfecting the service system of digital teaching support. By using and evaluation, promoting the in-depth integration of information technology and teaching, and the reform of network-based personnel training mode, teaching contents and teaching methods, Professional major categories need to meet the demands of independent learning students to provide a full range of learning support and services online teaching platform and teaching resources. However, in the previous work, due to the lack of understanding of digitization in the university leadership, and their not knowing how to use digitization in the development of physical education to cultivate new sports mode and to realize the pre-physical teaching simulation, so, in order to achieve the co-construction and sharing of high-quality teaching resources in the connection between the training of university personnel and the development of physical education, there is another problem: the lack of contact among schools. The so-called network digitalization is also an online commercial transaction, being unable to achieve each school independent coalition director.

Problems of Feedback System of Education Quality in the Continuity of Higher Education and Physical Education's Development. In most colleges and universities, the teaching quality feedback system of physical education is imperfect. The establishment and improvement of multi-modal teaching evaluation system cannot be implemented, and the evaluation of expert organizations are lacking in quality. The lack of attention and exerting the function of modern educational evaluation methods and techniques is important. There are always issues in strengthening professional setting, personnel training program formulation, quality management of practical teaching and implementation process. Establishing and perfecting specialized teaching quality assessment supervisory agencies cannot give full play to its due effectiveness. Constructing a national teaching management information system for higher physical education, and establishing the teaching status database for undergraduate colleges and vocational colleges, and due to the lack of experience, strengthening the dynamic monitoring and data management cannot achieve the expected results. 


\section{Solutions of Problems in the Continuity of Higher Education and Physical Education's Development}

The problems discussed above in the continuity of higher education and physical education's development are not to talk about the problems for asking, but for solving the problems involved in the continuity of higher education and physical education's development. We won't give solutions one by one in response to the above problems, but give the overall solution to the problem.

The Continuity of Higher Education and Physical Education's Development in the Level of Thoughts. As the cradle of talent cultivation, colleges and universities must give their eyesight a longterm perspective. Not only should they pay attention to the development of students in terms of intelligence, but also pay attention to the overall development of the student virtue and sports. This requires that college leaders must pay attention to the cultivation of students with physical education and convergence. While paying attention to the cultivation of intelligence, they should not ignore the development of physical education and organize school physical education teachers to visit and study so that the school can reach its proper height at the ideological level. So that the real college talent training and physical education at the ideological level can be barrier-free convergence.

The Solution of Teachers and Teaching Materials Problems in the Continuity of Higher Education and Physical Education's Development. As colleges and universities, we should regard colleges and universities as two aspects. On the one hand, the quality of teachers is low, and schools should strengthen the professional training of P.E. related personnel in schools, and continuously explore the related issues of visiting study and internal P.E. teaching staff from time to time, so as to improve the quality of teachers. Schools also should constantly guide teachers to promote heuristic, inquiry, discussion, participatory teaching, to encourage research teaching. Therefore, national and provincial key expert teachers must take the lead in the development of research teaching demonstration courses. Strengthening the integration of theory and practice, and promoting problembased, project-based, case-based teaching methods and learning methods. We should also strengthen the comprehensive practice of design and application of subjects to support students to carry out research learning, innovative experiments. To establish a comprehensive evaluation system of teachers' curriculum scores combining many aspects, such as ability and quality, and to constantly strengthen the normative, pertinent and effective teacher examinations. In view of the shortage of physical education teachers resources, colleges and universities should cooperate with specialized physical education institutes, to organize graduates and to practice in schools, in order to solve the shortage of teachers, and to continuously improve the treatment of physical education teachers so that they devote themselves wholeheartedly to teaching. In the construction of teaching material system, teaching materials should be continuously updated, keeping in line with the latest achievements. The establishment of a long-term mechanism for textbook construction focusing on improving the quality of personnel training and a selection mechanism for textbook evaluation should be based on the principle of selecting the best, the special and the new, making full use of teaching resources.

The Solution of Teaching Problems in the Continuity of Higher Education and Physical Education's Development. In view of the problems existing in the practice of teaching, colleges and universities in all localities should choose the subjects they teach in P.E. classes according to their environment. It is imperative that colleges and universities make half of their respective theories and practices, in this way, they can make students pay attention to practice as well as theoretical study while integrate theoretical teaching with practical teaching rather than boring teaching of isolation. If funds permitted, they should invest quantitative funds for the purchase of sports material. In the teaching practice, an evaluation system should also be established to prevent sheep-style management in the teaching of physical education. Even in amateur daily training, or in sports venues or open-air venues, we need to pay attention to make sure the funds, venues, equipment, full-time coaches, training time "five implementations." At the same time, paying attention to safety issues in practice. In sports 
practice, especially in strenuous exercise, safety is the biggest hidden danger of physical education. This requires that all unsafe risks be investigated in practical teaching and prevention measures should be taken simultaneously. Do teaching safely. In practice, colleges and universities should also set up awareness of building high-level sports teams and striving to cultivate high-level sports talent.

The Solution of Sharing Teaching Resources Problems in the Continuity of Higher Education and Physical Education's Development. In the course of cultivating university sports talents, it is not a university that fights alone, but all colleges and universities work together to make progress. This requires all colleges and universities to strengthen cooperation to achieve common theoretical results. To achieve this in three aspects, first, to strengthen the alliance of colleges and universities to make full use of the faculty advantages of colleges and universities. Not only to strengthen the exchange of teachers, but also to strengthen the exchange between students and students, to increase in learning and reference to grasp the theory of practice. Second, colleges and universities should hold sports competitions for a certain period of time. Sports competitions are an important part of school sports and an effective carrier for strengthening the integration of teaching and learning. Reforming and improving the management system of youth competitions to vigorously carry out the students' sunshine sports as the focus, after the conclusion of the game as a pillar, every spring and autumn, the school will hold track and field events in the school-based games, and according to local conditions often carry out class as a unit of student sports activities and competitions, so that everyone has sports, classes have physical activity, school sports characteristics. Regularly hold a secondary school sports games, held annually in the provincial youth students Sunshine Sports League. For students who reach the standard of athlete's level, the sports department shall timely issue the corresponding sports grade certificate. So, do the mutual teaching of physical education results.

The Solution of Teaching Quality Control Evaluation Problems in the Continuity of Higher Education and Physical Education's Development. In the teaching quality control evaluation, we should explore and establishing a self-assessment of colleges and universities as the foundation, the basic state of teaching basic state monitoring data to focus on the "to promote systematically, to make breakthroughs focally, to inherit and innovate, to integrate and upgrade, and to improve efficiency" principle, in-depth implementation of physical education and quality improvement project are needed, and we need to improve the national, provincial and school teaching quality construction system. Giving full play to teaching quality monitoring and evaluation, to make new breakthroughs in the key areas and weak links that affect and constrain the teaching quality of higher education in advancing the reform of physical education, strengthening the construction of physical education and improving the leading, demonstration and radiating role of physical education quality.

\section{Conclusion}

There is no doubt that the continuity of higher education and physical education's development is a topic worthy of constant exploration. The combination of the two should be continuously applied and explored in practice. Only when we find and solve problems in practice, can we make a bright future for our county's sports career, and raise the cultural level of athletes, and enable our country to be a big one in sports, promoting the mass development of sports by promoting the development in universities and colleges.

\section{References}

[1] Qu Hongqiang, The Research on the Construction and Proof of School P.E. Teaching Quality Control Evaluation System[D]. Fujian Normal University, 2012.

[2] Li Ying, Physical Education Teaching Research Based on Ethics [D]. Fujian Normal University, 2012. 
[3] Jiang Bo, From Competitive to Fitness: University Sports Humanistic Spirit Remodeling[D]. Southwest University, 2012.

[4] Wu Wei, Research on the Physical Education Performance Management in Colleges and Universities[D]. Hebei Normal University, 2013.

[5] 2005 Chinese Eminent Education Worker Style[A]. China Future Research Association, China Academy of Management Sciences, Peking University and the Education College, Henan University of Science and Technology. The Fourth China Educators Entrepreneurs Forum and 2005 China Education Hotspot Proceedings Symposium[C]. China Future Research Association, China Academy of Management Sciences, Peking University and the Education College, Henan University of Science and Technology: 2005: 217.

[6] Li Wenjing. Considerations that Employer to College Students Sports Quality[D]. Hunan Normal University, 2012.

[7] Chen Qi. Discussion on the Development of Physical Education in Colleges and Universities[D]. Beijing Sport University, 2002.

[8] Peng Qingwen. Research on the role of sports in Chinese universities in the new era[D]. Tsinghua University, 2009. 